\title{
Now, Imagine an Actually Existing Unicorn: On Russellian Worries for Modal Meinongianism
}

\section{Andreas de Jong ${ }^{1}$}

Received: 31 January 2019/Accepted: 28 March 2020/Published online: 23 April 2020

(C) The Author(s) 2020

\begin{abstract}
Modal Meinongianism provides the semantics of sentences involving intentional verbs Priest (Towards Nonbeing, Oxford University Press, Oxford, 2016). To that end, Modal Meinongianism employs a pointed non-normal quantified modal logic model. Like earlier Meinongian views Modal Meinongianism has a characterisation principle (QCP), that claims that any condition whatsoever is satisfied by some object in some world. Recently, Everett (The nonexistent, Oxford University Press, Oxford, 2013, 169, p. 36) has proposed an argument against QCP that, if successful, gives rise to problems identical to those Russell (Mind 14:530-538, 1905, p. 533) raised for Naïve Meinongianism, namely that it allows for true contradictions, and allows us to define anything into existence. Everett claims that the ordinary meanings of "actual" license an inference pattern, such that if an object satisfies Actual $A$ at some world, then that object satisfies $A$ in the actual world. Given that actual world is the designated point of evaluation for truth simpliciter, QCP would fall prey to Russell's criticisms. As opposed to Everett, I argue that, even if we grant Everett the assumption that "actual" is a modal indexical that rigidly refers to the actual world, it does not conform to the inference pattern above. This is because when an object satisfies Actual $A$ at some world, this alters the assertoric force of "actual", because "actual" is interpreted in the scope of some modal or intentional operator. I also explain that Everett's proposed example carries existential commitment because the problematic noun-phrase occurs outside the scope of a modal or intentional operator.
\end{abstract}

Keywords Actual - Characterisation · Force - Indexicals - Modal Meinongianism · Scope

Andreas de Jong

andreas.dejong@manchester.ac.uk

1 Department of Philosophy, The University of Manchester, Humanities Bridgeford Street, Room 2.48, Oxford Road, Manchester M13 9PL, UK 


\section{Introduction: Modal Meinongianism and Characterisation}

Modal Meinongianism was proposed by Priest (2016) to provide a semantics for intentional verbs. Between those verbs, Priest distinguishes between intentional predicates and intentional operators. The difference is that the former verbs $\Phi$ have a noun-phrase complement (NP $\Phi$ s NP), whereas the latter verbs $\Psi$ have a sentential complement (NP $\Psi$ s that S). I will focus on the semantics of the latter, since they are most important for the discussion. Intentional operators are such that their sentential complements can be false. In order to provide the semantics of intentional operators, Priest employs a non-normal pointed model of modal logic. ${ }^{1}$

This non-normal pointed model has two features that are relevant to the problem at hand. First, it consists, besides of a set of possible worlds, of a set of non-normal worlds as well. Non-normal worlds can violate the rules of logic that govern reality. This feature of non-normal worlds leads to what Priest calls the "Primary Directive" (2016/2005, p. 187), which is that "Everything holds at some worlds, and everything fails at some worlds" (2016/2005, p. 187). In order to determine relative possibility, this model also has accessibility relations between worlds. I will stipulate that those relations are between worlds that are equivalent with respect to the logic that governs them.

Second, the actual world @ is the designated point of evaluation for truth and validity: When a sentence is true, this means that it is true at @, a formula is valid simpliciter if and only if it is true in all worlds that are accessible from @. In terms of providing the semantics of intentional operators, the first two features of this nonnormal pointed model are important. The semantic interpretation of intentional operators is a function from an ordered pair of an individual and a world to a world. For instance, "I imagine that there is going to be a sea-battle tomorrow" is true at a world $w$ if and only if at world $w_{1}$ selected by the operator "...Imagine that..." with me and $w$ as arguments "there is going to be a sea-battle tomorrow" is true. In order for "I imagine that there is going to be a sea-battle tomorrow" to be true simpliciter, it needs to be true at the actual world @. Hence, the world $w_{2}$ selected by the operator with me and @ as arguments needs to make true the sentential complement.

Third, Modal Meinongianism employs a qualified characterisation principle (QCP) for Modal Meinongianism, just like other forms of Meinongianism. Unlike other forms of Meinongianism, Modal Meinongianism's characterisation principle is not invoked to provide identity conditions for objects, but rather in order to capture the boundlessness of imagination: "We would seem to be able to think about, imagine, tell a story about, an object with any old bunch of properties that we care to put together" (Priest 2016/2005, p. 83). ${ }^{2}$ To capture this boundlessness of imagination QCP mobilises worlds:

\footnotetext{
${ }^{1}$ In what follows, I only elicit details that are directly relevant to the problem that I am discussing in this paper. For more details, consult Priest (2016/2005, pp. 8-25).

2 According to Meinong, nonexistent objects are supposed to be characterised by the properties that they have $(1960 / 1904$, p. 82). In this sense, it seems reasonable to suggest that Meinong wanted to identify objects by the properties that they are characterised by. In Meinong's wake, other Meinongians have
} 
QCP Let $A(x)$ be any condition; this characterizes an object $C_{A}$. And $A\left(C_{A}\right)$ is true-maybe not at this world, but at other worlds. (2016/2005, p. 84)

QCP follows from the Primary Directive. As said, per the Primary Directive of nonnormal modal logic, everything holds at some world and does not hold at some world. Hence, the Primary Directive entails that any condition $A(x)$ is satisfied by some object at some world, because everything holds at some world.

The problem that I discuss for QCP resembles the problem that is generated with the introduction of an actuality operator. According to its originator, namely Beall (2006), this actuality operator $(\mathfrak{A})$ is supposed to have the same inference rule in all worlds, i.e. be a uniform operator. For $\mathfrak{A}$ the inference rule I-Act is:

I-Act $\mathfrak{U} A$ is true at $w$, just if $A$ is true (at @), for any world $w$ (Beall (2006).

The problem with $\mathfrak{A}$ conforming to I-Act is that it gives rise to two criticisms that Russell (1905, p. 533) levels against the characterisation principle of what has been called "Naïve Meinongianism" by Berto (2013a, p. 85). ${ }^{3}$ This characterisation principle (CP) states

CP For any specifiable condition $A$, there is an object $o$, such that $A(o)$ is true.

Russell criticises CP for two reasons. First, CP allows that objects satisfy true contradictions: for any specifiable condition $A$, there is a specifiable condition $A \& \neg A$ that is satisfied by some object $o$. If so, $o$ realises a true contradiction. Second, CP allows one to define anything into existence, since for any specifiable condition $A$, there is a specifiable condition $A \&$ Existence that is satisfied by some object. Of course, because of the qualification of QCP that condition $A$ is realised in some world, QCP is able to evade Russell's criticisms.

However, the actuality operator introduced by Beall (2006) revives Russell's original two criticisms for QCP. It revives the first criticism because, by $\mathbf{Q C P}$, for any condition $A$, there is $\mathfrak{U}(A \& \neg A)$ that is satisfied by $o$ at $w^{*}$. By I-act if $w^{*} \models \mathfrak{U}(A(o) \& \neg A(o))$, then $\quad @ \models \mathrm{A}(\mathrm{o}) \& \neg A(o)$. I-act also revives Russell's second criticism because, by QCP, for any condition $A$, there is $\mathfrak{A}(A \&$ Existence) that is satisfied by some $o$ at $w^{* *}$. By I-act if $w^{* *} \models \mathfrak{U}(A(o) \&$ Existence $(o))$, then $@ \models(\mathrm{A}(\mathrm{o}) \&$ Existence $(o))$. This result entails that QCP can define anything into existence. Even though $\mathfrak{A}$ is artificial, Beall claims that the inference rule is made plausible by the general conception of actuality, such that "that 'actually' is always referring back to what's going on in our base (or actual) world" (2006).

Sauchelli (2012) lends extra support for the need for an operator like the one proposed by Beall by pointing to the notion of actuality being central to the understanding of fictions: "a central feature of some fictional objects, [...] is that they are represented, by agents in our world, as existing at our world and as having

Footnote 2 continued

adopted similar characterisation principles to identify objects different forms of Meinongianism (cf. Parsons 1980, p. 21; Zalta 1988, p. 19). For Priest's views on identity, see Priest (2016, pp. 30-55).

3 Berto calls the position "naïve", because CP is likely to be a Russellian caricature of Meinong's position. 
relations to objects that are part of our world" (Sauchelli 2012, pp. 141-142). Insofar as Modal Meinongianism rejects the inference rule for $\mathfrak{A}$, it "is either inconsistent (if it embraces an unrestricted principle of characterization) or incomplete (for it cannot accommodate certain properties attributed to fictional characters)" as a theory of fiction, according to Sauchelli (2012, p. 144). Given that Meinongians assume that they are supposed to give an adequate account for fiction, this motivation seems plausible.

In response to the problem generated by Beall's actuality operator, both Priest (2011, pp. 249-250) and Berto (2013b, p. 271) point to the Primary Directive of non-normal modal logic: any well-formed formula is true in some worlds and false in some other worlds. In that sense, the stipulation of an operator that has the same inference rule in all worlds goes against the nature of non-normal worlds. Given QCP, the only constraint is that a condition $\mathfrak{U} A$ is satisfied by some object $o$ in some world $w$, where $w$ does not need to be one where the inference rule for $\mathfrak{A}$ conforms to I-act. Hence, Russell's first and second worry are not revived.

The argument by Everett that I am about to discuss does not point to a stipulated use of "actual", but rather takes into account the ordinary meaning of "actual". The argument is that the ordinary meaning of "actual" licenses an inference pattern like I-act. I tackle Everett's argument as follows.

First, I describe how Everett's argument differs from the argument by Beall (2006) and Sauchelli (2012) by appealing to the ordinary meanings of "actual". In this section, I also argue that Everett needs an indexical analysis of "actual" to get his argument off the ground. This indexical analysis is needed to let "actual" conform to the inference rule I-Act for the actuality operator introduced by Beall.

Second, granting the assumption that "actual" is an indexical, I propose a solution inspired by Lewis' narrow and wide scope reading of "actual". As opposed to Lewis, I maintain that "actual" refers to the actual world, even if it occurs in the scope of an intentional or modal operator. In this sense, I maintain that indexicals always take wide scope. However, I do maintain that the inference pattern of indexicals is qualified when they occur in the scope of an intentional or modal operator. This qualification blocks "actual" from conforming to I-act.

Third, I explain that the existential import of Everett's initial compelling example is not explained by the use of "actual". Rather, the existential import of his example is explained by a mistaken presupposition. This presupposition forces the nounphrase to occur outside the scope of the modal operator and thus forces noun-phrase to be referential in the actual world, when taken at face value. However, on such a reading the initially compelling example sentence is false.

\section{Imagining Actual Existent Unicorns}

Priest's and Berto's rejection of Beall's proposed uniform operator is adequate because Beall employs a stipulated use of "actual". Because the use is stipulated, there are no intuitions about what such a word might mean in the context of fiction or in an intentional context. But Beall's argument can be made more pertinent if the 
ordinary meaning of "actual" conforms to I-Act. Everett maintains that this is the case in his reply to Priest's strategy to adopt QCP:

[T]his strategy itself raises a number of problems. For one thing suppose I tell a story about an actually existing actually golden actual mountain, mistakenly supposing there is such a thing and that I am telling a story about an actual entity. It is hard to see how my words could fail to have their normal meanings. But then it seems the relevant Meinongian object should have the property of actually existing; that is to say it should actually exist. (Everett 2013, 169, fn. 36, his emphasis).

Everett portrays the situation to be such that the sentence

1. Anthony told me a story about an actually existing actually golden actual mountain.

has existential import, in the sense that if sentence 1 is true, then something satisfies "is an existent golden mountain" at the actual world. Given Everett's reasoning, the existential import of sentence 1 is due to the ordinary meaning of "actual". In general, the argument would be that if an object $o$ satisfies the condition Actually $A$ at some world $w$, then this entails that something satisfies $A$ at the actual world. Since Everett appeals to the "normal meanings" of "actual", he maintains that the ordinary use of "actual" conforms to the inference pattern I-Act.

Everett does not tell us what the normal meanings of "actual" are. In order to develop his argument, I first introduce two candidate meanings of "actual". The first is that "actual" is a modifier which resembles the meaning of the modifier "real". The second is that "actual" is a focus particle. In this section, I will argue that the first two proposed meanings do not provide the inference pattern I-Act. Hence, in order for Everett's argument to be successful, he needs to adopt the position that "actual" is an indexical expression. Contrary to the first two proposed meanings of "actual", the indexical meaning can conform to the inference pattern I-Act, because indexicals always take wide scope. To that end, I introduce two candidate indexical meanings for "actual". The first is that it resembles the modifier "present" that refers to the time of utterance, the second is that "actual" is a modal indexical that refers to the world of utterance.

Let us first review the first two meanings. The first proposed meaning, that "actual" conforms to the semantics of the modifier "real", suggests itself when we turn to the Oxford Dictionary, which proposes that "actual" means "Existing in fact, real; carried out, acted in reality". This meaning of "actual" bears out in the following examples:

2. Joffrey is a usurper; Daenerys is the actual heir to the Iron Throne.

3. Some call Trump the most powerful man in the world. Behind the scenes, it's actually Putin who calls all the shots.

4. The actual fact is that Britain will be financially worse off with a hard Brexit.

5. The estimate was much less than the actual cost.

6. The fact that some women will not be able to apply, that's where the actual sexism is. 
In sentences 2-6, the form of "actual" can be replaced with the corresponding form of real without changing the truth-conditions. Like "real", "actual" can function as a modifier of predicates and sentences. In terms of predicates, the predicate "real witch" is co-extensive with "witch", and is contrasted with "fictional witch" or "imaginary witch". In similar vein, "actual witch" is co-extensive with "witch". The adverb "real" can modify a sentence $S$ as well: "really, S" is true if and only if "S" is true. Similarly, "actually, $S "$ is true if and only if " $S$ " is true.

This semantic role of "actual" as a modifier like "real" does not present a problem for QCP. That modifier takes an extension of a sentence or a predicate and returns the same extension. If the sentence is true, then the modified sentence is true; if an object satisfies the predicate, then the object satisfies the modified predicate as well. In terms of QCP, if $o$ satisfies Actual $A$ on $w$, then $o$ just satisfies $A$ on $w$. Hence, the inference pattern for "actual" as resembling the modifier "real" does not resemble I-Act at all, and, hence does not provide the natural language underpinning for Everett's argument.

The second proposed meaning of "actual", namely as a focus particle, suggests itself in the following example:

7. The book could be condensed into half the space, but what of the actual content?

In sentence 7, the adjective "actual" does not add any semantic content, but is merely used to focus attention to a particular aspect of the book that is supposed to be important by the speaker. This shifting of attention is what a focus particle is supposed to do. Sentence 7 suggests that the book can be halved, but that would also mean the most important aspect of the book, i.e. the content, will suffer. That "actual" is used as a focus particle entails that if we were to leave out "actual", but just put focal stress on "content", we would say the same as when we utter sentence 7.

The role of "actual" as a focus particle does not present a problem for QCP either. Focus particles do not add any semantic content. In sentence 7, "actual content" denotes the same thing as "content" with focal stress. So, when it comes to QCP, to an object $o$ satisfies Actual $A$ on $w$, then $o$ just satisfies $A$ on $w$. The inference pattern for "actual" as a focus particle does not resemble I-Act at all, and, hence does not provide the natural language underpinning for Everett's argument.

In order for Everett's argument to work, "actual" needs to be an indexical. Indexicals have the feature that their semantic content is determined by the context of utterance, not by context of evaluation. In a more technical sense, that what indexicals refer to is determined by the context of utterance means that they always take wide scope (Kaplan 1989). To see how this works, compare the following examples:

8. On January first, when I was in Deventer, I said I would be here now.

9. On January first in Deventer I said I would be in Deventer on January first.

10. On January first in Deventer I said I would be at the Metametaphysical Club on January 11. 
In sentence 8, the indexicals "here" and "now" refer to a place and a time respectively. If those expressions would take narrow scope, then the embedded sentence "I would be here now" would be interpreted by the context of evaluation, i.e. on January first in Deventer. The resulting interpretation would then be that I was saying on January first in Deventer that I would be in Deventer on January first. In that case, sentence 9 would be the correct interpretation of sentence 8 . However, sentence 9 is not the correct interpretation of sentence 8 , but sentence 10 might be if I utter sentence 8 at the Metametaphysical Club on January 11. This is because the reference of indexical expressions is determined by the context of utterance, not by the context of evaluation.

This feature of indexical expressions can help with Everett's argument in the sense that when we use "actual" in a condition Actual A, then "actual" has to be interpreted as referring to the world of the context of the utterance. If that context of utterance is the actual world, then "actual" refers to the actual world. Such a result, of course, would revive Russell's worries, because then the inference pattern for "actual" would resemble I-Act.

A first candidate indexical meaning of "actual" is similar to the modifier "present". This meaning is suggested by sentence 11:

11. We will use actual income to calculate past income.

As an indexical modifier, "present" modifies the extension of predicates to an extension to which the predicate applies at that time. As sentence 11 bears out, we can contrast "actual income" with "past income" or even "future income".

In order for this indexical meaning of "actual" to conform to I-Act, it is required that a reference to the time of utterance entails a reference to the world of utterance as well. If so, the condition $A$ also has to be satisfied at the actual world. In that case, if the context of utterance for "actual" is the actual world, then a condition of Actual $A$ being satisfied by some object at some world entails that $A$ is satisfied at the actual world. Such a result, of course, would revive Russell's worries, because then the inference pattern for "actual" would resemble I-Act.

If some find the assumption that a reference to the time of utterance entails reference to the world of utterance contentious, I submit a second candidate indexical meaning of "actual". This meaning follows Lewis' indexical analysis of "actual" (1970, pp. 184-187; 1973, pp. 85-86), also defended by Salmon (1987, pp. 76-78). According to Lewis, "actual" refers to the world of the context of utterance. If uttered at this world, "actual" is co-referential with "this world". Lewis proposes the following rules of application for "actual":

\footnotetext{
4 Perhaps someone might argue that this use of "actual" conforms with the use of "real". The difference between the role of "actual" as the modifier "present" and its role as the modifier "real" is that we can maintain that past and future income is still income. The only way the modifier "present" aligns with the modification of "real" is if we assume that natural language carries a commitment to presentism, i.e. that only what is present is real. If natural language carried such a commitment, it would entail that future income and past income is not really income, because past income is not real anymore and future income is not real yet (if in the future). However, I am not willing to commit to this.
} 
[A]t any world w, the name "the actual world" denotes or names w; the predicate "is actual" designates or is true of $\mathrm{w}$ and whatever exists in w; the operator "actually" is true of propositions true at w, and so on for cognate terms of other categories. (1970, p. 185).

Before dismissing these inference rules for "actual" as too remote, please note that these proposed rules of application have a striking resemblance to the rules of application for the modifier "real": In a world, "is real" designates what exist at that world, "really" is true of propositions in that world, and for predicate " $P$ ", "real $P$ " designates what " $P$ " designates. In that sense, this indexical analysis of "actual" is at least consistent with the linguistic data generated under the modifier "real".

Given Lewis' indexical analysis of "actual", any occurrence of "actual" takes wide scope. And if we interpret Everett's example above as featuring the indexical notion of actuality, then it would seem that the phrase "an actually existing actually golden actual mountain", even as it occurs within the story context, entails that the actual world features an existent golden mountain. Given QCP, for any condition actually existent $A$, there is an $o$, such that actually existent $A(o)$ at some world $W$. Given that "actually" operates with wide scope and is uttered at the actual world, actually existent $A$ being satisfied by $o$ at $w$ entails $o$ satisfies existent $A$ at the actual world. Such a result, of course, would revive Russell's worries, because then the inference pattern for "actual" would resemble I-Act. Such an analysis, thus, would be what Everett requires for a natural language meaning of "actual".

\section{Scope and Force}

For the sake of argument, I will grant Everett the assumption that "actual" is an indexical that refers to the actual world. As such, I accept that "actual" takes wide scope. However, I resist that "actual" follows I-Act. This is because interpreting "actual" at $w$ as conforming to I-Act does not take into account the modal qualification of interpreting "actual" at $w$. This qualification is put into effect by indexicals occurring in the scope of modal and intentional operators. The indexicals are not affected such that "actual" does not refer to the actual world when it occurs in the scope of such an operator. However, when we talk about what is actual at some world $w$, we do not speak about what is actual, but about what could (or could not) have been actual. This qualification alters the inference pattern of indexicals like "actual".

The solution suggests itself when we take into account examples generated by Lewis (1970). Even though I do not agree with his interpretation of the examples, the examples themselves do suggest the solution that I argue for. Take the following two examples (1970, p. 185):

12. If Max ate less, he would be thinner than he actually is.

13. If Max ate less, he would actually enjoy himself more. 
Lewis himself claims that "actual" takes narrow scope in sentence 13, as opposed to the wide scope it takes in sentence $12 .^{5}$ In sentence 12 , "actual" takes wide scope, as usual. The narrow scope use of "actual" can be ruled out as follows. If "actually" would refer to the world of evaluation $w$, then sentence 12 would be trivially false, because it is false at any possible world $w$ that Max is thinner at $w$ than he is at $w$. Hence, the reasonable interpretation for sentence 12 is that "actual" refers to the world of utterance: at $w$, Max is thinner than he is at $v$, where $v$ is the world of utterance. So, "actual" takes wide scope in sentence 12 .

Lewis claims that "actual" in sentence 13 takes narrow scope. So, according to Lewis, "actual" in sentence 13 refers to the world of evaluation $w$. Lewis could motivate the narrow scope reading of "actual" in sentence 13 by claiming that if "actual" would take wide scope, sentence 13 would be trivially false. This becomes apparent when we read sentence 13 as elliptical for "If Max ate less, he would actually enjoy himself more than he actually does". With "actual" taking wide scope, sentence 13 would express that Max is happier in world of utterance $v$ than he is in $v$, which is trivially false. Hence, it seems more reasonable to suggest that "actual" takes narrow scope: In world of evaluation $w$ Max enjoys himself more than he does in $v$.

If Lewis is correct that the narrow scope reading of "actual" refers to the world of evaluation, then there is a solution for Everett's objection against QCP: If "actual" would always take narrow scope in the context of fiction and intentionality, then, if condition Actual $A$ is realised by object $o$ at $w$, that just entails that $o$ satisfies $A$ on $w$. This would entail that "actual" does not follow I-Act, and thus would not entail that $o$ satisfies $A$ at @. Therefore, QCP can hold in full generality, if "actual" takes narrow scope. Unfortunately, Lewis is incorrect that "actual" takes narrow scope.

One reason to be skeptical of this solution inspired by Lewis is that it is uncommon that indexicals refer to something else than the context of utterance. As mentioned in the previous section, indexicals always take wide scope, because the content of indexicals is determined by the context of utterance. This was demonstrated with example sentences 8-10. With more familiar indexicals, interpreting them as referring to the context of evaluation can only be done if there is a context shift, where the context of utterance is interpreted as having shifted to the world of evaluation. As such, those indexicals still take wide scope, but what has changed is the interpretation of what the context of utterance is. Familiar examples are the historical present, the guidebook's use of "here", and recorded messages. Take the following vignettes:

14. In May 1940, Neville Chamberlain has just resigned as prime minister and has suggested to his majesty King George to appoint Winston Churchill. Now, a lifelong dream of Winston Churchill has been fulfilled: he finally has the chance to take up the office of Prime Minister and confront the aggressive politics of Nazi Germany.

\footnotetext{
5 Lewis calls uses "primary sense" and "secondary sense" for wide and narrow scope respectively (1970, p. 185). I will continue to use wide and narrow scope instead.
} 
15. Special forces have Bin Laden in their sights. Now, the president has an important decision to make.

16. The eternal city of Rome features many beautiful historical landmarks. The Laterane hill is the part of the city which contains most of Rome's eldest historical remnants. Here we find the old Colosseum, the Forum Romanum, and the four-layered church of San Clemente.

17. Hello, I am not here now. Leave a message after the beep.

In vignettes 14 and 15 , the context of utterance is shifted to the narration of the moment Winston Churchill became prime minister and Barack Obama being in the situation room respectively. In both examples, the indexical "now" does not refer to the present as you are reading this vignette or as I am writing this vignette down, but refers to where we are in the development of the historical narration. In vignette 14, the historical present reading of "now" is rather obvious, because Winston Churchill has passed away and is, as you read this or as I am writing this down, not able to do anything, let alone confront the aggressive politics of Nazi Germany. In like fashion, "now" in vignette 15 refers to the moment in the development of the story where the president learns, in the situation room, that the Special Forces are ready to execute Bin Laden. In vignette 16, the context of utterance is shifted to the place where the narrator is in the development of the guided tour told in the guidebook, where "here" obviously refers to Laterane hill, not to the place where we are when we read the guidebook or where the author was when she wrote this section. In vignette 17 , the familiar recorded answering machine message indicates that at the moment that you are supposed to hear the message, indicating that the person uttering the message is at another place than when she recorded the message. Hence, "here" is supposed to refer to where you are calling and"now" refers to the moment you are calling.

Vignettes 14-17 illustrate that indexicals only come to refer to the context of evaluation through a shift in the context of utterance. Perhaps Lewis might claim that such a context shift has occurred in the interpretation of sentence 13. However, in order for Lewis to achieve the desired result, the context-shift to the world of evaluation would have to occur before the sentence, and would have to shift back to the world of utterance before the elided second occurrence of "actual". How context shifts occur is a matter of controversy. Predelli $(1998,2005)$ has argued that context shifts can occur through the author's intention, whereas Recanati (2010, pp. 192-194) argues that the context shift occurs by pretending that the author is at the place indicated by the story, and thus is different than what it really is. I will not arbitrate between these positions, but merely show that it is not plausible to suggest that on either account such a context shifts has occurred for sentence 13 .

On Predelli's (1998, p. 403) proposal, there is a distinction between contexts of utterance and intended contexts of interpretation. In a proper context, the context of utterance coincides with the intended context of interpretation; in an improper context, the intended context of interpretation differs from the context of utterance (Predelli 1998, p. 410). On this account, then, vignettes 14-17 should be interpreted on a different context than the context of utterance. a speaker can shift a context of interpretation through their intention to a different context than the context of 
uterance. Take vignette 17 as an example. In order to interpret 17 correctly, we should interpret 17's context of interpretation as the moment the speaker intends the hearer to hear the answering machine's message, not the moment the speaker utters 17. Sentence 13 should not be interpreted in the same fashion, but should be interpreted as being uttered by the speaker at the same time and place as we are when we hear the message. Given Predelli's proposal, it is not at all plausible that a context shift has occurred in the interpretation of sentence 13.

On Recanati's (2010, pp. 192-194) proposal, the context shift is understood appropriately through imagining that the speaker utters the vignette in a different (fictional) context of utterance. Vignettes 14 and 15 are examples where we imagine that the narrator is narrating the events as they unfold, whereas for vignette 16 we imagine that the guide is at the place that the book tells us about. It is not plausible to suggest that our interpretation of 13 involves any imagination that the speaker is at some different context of utterance, say that the speaker is at the world where the antecedent is satisfied. On Recanati's account, then, it is not plausible to suggest that a context shift has occurred in our interpretation of sentence 13 either.

Another reason to be skeptical of Lewis' claim that "actual" takes narrow scope in sentence 13 is that the interpretation of sentence 13 is consistent with "actual" referring to the actual world. In entertaining the counterfactual conditional 13, we entertain what would have been actual. If, at the actual world, the counterfactual antecedent would have been true-namely if Max ate less at the actual world, then the consequent would have been true at the actual world as well-i.e. Max enjoys himself more at the actual world then he would if he ate as much as he really did. ${ }^{6} \mathrm{~A}$ sketch of the semantics of sentence 13 is compatible with "actual" still referring to the actual world. To see that sentence 13 is not an isolated example, compare the following:

18. I imagined that Hillary Clinton was the actual President of the United States. 19. Mary told me a story, according to which Beyoncé is an actual lizard person. 20. John could have been an actual belly dancer.

In sentence 18-20, "actual" refers to the actual world as well. Sentence 18 is true if and only if I imagine that Hillary Clinton is President of the United States in the actual word. Sentence 19 is true if and only if Mary told me a story according to which Beyoncé is a lizard person in the actual world. Sentence 20 is true if and only if John could have been a belly dancer in the actual world. Hence, sentence 18-20 are compatible with "actual" referring to the actual world, and are not compatible with "actual" referring to the world where the condition is realised.

Up to this point, I have used "narrow scope" purely in the way that the reference of an expression can be altered if it falls within the scope of an operator. What it means for an indexical expression to take narrow scope is that its reference is to the

\footnotetext{
${ }^{6}$ I apologise for being sketchy here. The semantics of cross-world comparisons is notoriously difficult, see Wehmeier (2012) and Kocurek (2016) for a discussion. Insofar as possible world semantics does not give us enough expressive tools to deal with those comparisons, this is a legitimate issue that should be addressed. However, insofar as this is a problem for Modal Meinongianism, it is a problem for any world semantics, not just the non-normal world semantics of Modal Meinongianism.
} 
context of evaluation rather than to the context of utterance. Lewis suggests that this is the case for "actual" in sentence 13 and I disagree. However, there is another way indexicals can be affected when they fall within the scope of an intentional or modal operator, which provides the solution for Everett's objection against QCP. Even though "actual" refers to the actual world in sentence 13 and sentences 18-20, "actual" is barred from conforming to I-Act when it occurs in the scope of that operator, because its inferential pattern is qualified by that respective operator.

If an object $o$ is imagined to be Actual $A$ that does not entail that $o$ is Actual A. If $o$ is Actual A according to some story, then it need not be Actual A. And if $o$ only could have been Actual $A$, then $o$ is not Actual A. In general, to say that $o$ is Actual $A$ at some world $w$, is to say that $o$ would have been an actual $A$ at the actual world. And to say that $A(o)$ would have been actual does not entail that $A(o)$ is actual. In that sense, an embedded reading of "actual" does not conform to I-Act. Insofar as an object satisfies condition Actual $A$ at some world $w$, then $w$ captures what would have been actual.

Suppose we follow Lewis (1973, p. 84) in taking possible worlds to be ways the world could have been, and follow Yagisawa (1988, p. 83) and Nolan (1997, p. 536-541) in taking non-normal worlds to be ways the world could not have been. According to that conception, the incomplete definite description "the world" denotes the actual world. Thus, insofar as other worlds are ways the world could have been, they are ways the actual world could have been. In imagining, we imagine ways the actual world could have been; in telling stories, we tell stories according to which the actual world is a certain way; in entertaining what could have been, we entertain what the actual world could have been like. Insofar as entities satisfy the condition Actual $A$ at some world $w$, that does not entail any consequence other than that they satisfy $A$ at $w$. This is because $w$ is already supposed to be a way the actual world could or could not have been.

In non-normal world semantics, each of the sentences 18-20 has the truth condition that some world is such that the condition embedded is true at that world. Sentence 18 is true if and only if the world $w$ selected by the imagination operator taking me and the actual world as arguments makes true that Hillary Clinton is the actual President of the United States. Sentence 19 is true if and only if world $w^{\prime}$ selected by the story operator with Mary and the actual world as arguments makes true that Beyoncé is an actual lizard person. Sentence 20 is true if and only if a world $w^{\prime \prime}$ that is possible relative to the actual world makes true that John is an actual belly dancer. Those conditions that are satisfied at other worlds, however, need to be qualified because those worlds are ways the actual world either could or could not have been.

In this sense, a condition being realised at some other world $w$ carries an implicit reference to the actual world, because that world realises a way the actual world could have been. To see this, compare sentences 18-20 to their counterparts that lack "actual":

$18^{\prime}$ I imagined that Hillary Clinton was the President of the United States.

$19^{\prime}$ Mary told me a story, according to which Beyoncé is a lizard person.

$20^{\prime}$ John could have been a belly dancer. 
Notice that sentences $18^{\prime}-20^{\prime}$ have the same truth-conditions as $18-20$ respectively. Like with sentences $18^{\prime}-20^{\prime}$, there is no commitment to the condition following "actual" being realised at the actual world in order for sentences 18-20 to be true. In the actual world, Hillary Clinton is not the President of the United States, nor is Beyoncé a lizard person, nor is John a belly dancer. In sentences 18-20, possible world semantics represents the state of affairs at the designated world $w$ as that for the conditions mentioned "is the President of the United States", "is a lizard person", and "is a belly dancer" are modified by "actual". In modifying those conditions, sentence 18 talks about how I imagined that the actual world to be, namely that Hillary Clinton was the President of the United States. In like fashion, sentence 19 reports that Beyoncé would be a lizard person if the actual world would be like what is represented in the story. Similarly, sentence 20 reports that the actual world could have been such that John would be a belly dancer.

This qualification by modal and intentional operators is by no means restricted to "actual". A quick comparison with "present", another indexical expression, bears out a similar result:

18" I imagined that Hillary Clinton was the present President of the United States. $19^{\prime \prime}$ Mary told me a story, according to which Beyoncé is a present lizard person. $20^{\prime \prime}$ John could have been a present belly dancer.

"Present" refers to the time of utterance at the actual world. However, what is imagined to be present, what is present according to a story, or what could have been present is not what is present. In that sense, that the condition Present $A$ is satisfied by some $o$ at some $w$ does not entail that $o$ satisfies $A$ in the actual world. In similar fashion, thus "present" does not conform to I-Act either. It seems, thus that the inference pattern of "present" is qualified by occurring in the scope of an intentional or modal operator as well.

The approach that I have set out for 18-20 also extends to the interpretation of sentence 13. In sentence 13, the consequent "he actually would have enjoyed himself more", which I take to be elliptical for "he actually would have enjoyed himself more than he actually does", involves a comparison between what would have been actual, namely how much Max would enjoy himself, and what is actual, namely the extent to which Max actually enjoys himself. For sentence 13, it also goes that the actuality operator does not make a difference. Like sentences 18-20 are expressed without actuality operators by sentences $18^{\prime}-20^{\prime}$, we can express 13 by "If Max ate less, he would enjoy himself more (than he does)". In a modal comparison sentence like 13, the second part of the comparison is interpreted as not modally qualified. It pertains to what is actual, not what would have been actual if the antecedent were true. In this way, an internal contradiction is avoided, because what would have been actual can be more than what is actual. ${ }^{7}$

\footnotetext{
7 Thanks to an anonymous reviewer for bringing this to my attention.
} 


\section{Existential Import and Scope}

The last element of this article involves how the existential import of sentence 1 can be explained if "actual" does not conform to I-Act when it occurs embedded in an operator sentence. The explanation I offer is that the existential import of sentence 1 is forced by the phrase "an actually existent actual golden actual mountain" being interpreted as outside the scope of the intentional operator. To see how this works, consider that if my claim that "actual" does not force existential commitment when it occurs in the scope of an intentional or modal operator is correct, then it should follow that sentence 1 has the same commitments if the expression "actual" in the noun-phrase is omitted. For that reason, compare the following translation of sentence 1:

\section{$1^{\prime \prime}$. Anthony told me a story about an existing golden mountain.}

In order for sentence $1^{\prime}$ to be true, there has to be an existent golden mountain in the actual world, just as there has to be if sentence 1 is true. To contrast, sentence 13 does not come with a similar commitment. The difference between the occurrences of "actual" in sentences 1 and 13 is that in 1 "actual" does not occur in the scope of an operator (and is thus not qualified in the way the occurrence of "actual" in sentence 13 is), but takes wide scope. In that sense, "actual" is not essential for the existential import of sentence 1. What is essential, however, is that the noun phrase takes wide scope. Let me demonstrate why the noun-phrase takes wide scope in sentence 1.

Everett describes the situation for sentence 1 as the situation where the narrator mistakenly presupposes that there is an actually existent actually golden actual mountain and that he tells a story about that supposed mountain. In that sense, the noun-phrase "an actually existent actual golden actual mountain" occurs outside the scope of a story-telling operator. Hence, if sentence 1 is true, "an actually existent actual golden actual mountain" is supposed to denote an object in the actual world. Hence, sentence 1 should be taken to be equivalent to de re construction $1^{\prime \prime}$ :

1" There is an actually existing actual golden actual mountain, such that Anthony told me a story about it.

Sentence $1^{\prime \prime}$ is clearly false, because, there is no actually existing actual golden actual mountain in the actual world, but only in the world that models the presuppositions of the narrator. Sentence 1 is, thus, false.

Sentence 1 can be interpreted as true if we play along with the mistaken presuppositions of the author and reinterpret the sentences he expresses accordingly. ${ }^{8}$ Because the storyteller mistakenly presupposes that there is a thing that satisfies the description, the storyteller refers to the thing that supposedly satisfies the description. According to Modal Meinongianism, there is such a thing. However, it does not satisfy "is an existent golden mountain" in the actual world,

\footnotetext{
8 Such a situation is comparable to a case described by Donnellan (1966), where the definite description "the man drinking a Martini" is supposed to denote a man who is really drinking water. Compare fictionalist descriptions (Kroon 2000, 2003) of the situation where we are playing along with the presuppositions of the speaker.
} 
because nothing satisfies that description in the actual world. Rather, the object satisfies that description in the world which models the suppositions of the storyteller. Strictly speaking, "Anthony told me a story about something that he supposed to be an existing golden mountain" is true, not sentence 1, nor sentence 1 ', nor sentence $1^{\prime \prime}$.

Summarising, the existential import generated by Everett's example is not generated by the inference pattern of "actual" when it is realised at some world $w$. Even if we grant Everett the assumption that "actual" is an indexical that refers to the actual world, when a condition Actual $A$ is realised by some object at some world, the force of "actual" is altered such that it does not conform to I-Act. Hence, a condition Actual $A$ is realised by some object at some world does not that $A$ is realised by $o$ at the actual world. As such, the ordinary meaning "actual" does not revive Russell's worries. Rather, the existential import of Everett's example is explained by the noun-phrase "actual existent actual golden actual mountain" occurring outside the scope of intentional and modal operators.

Open Access This article is licensed under a Creative Commons Attribution 4.0 International License, which permits use, sharing, adaptation, distribution and reproduction in any medium or format, as long as you give appropriate credit to the original author(s) and the source, provide a link to the Creative Commons licence, and indicate if changes were made. The images or other third party material in this article are included in the article's Creative Commons licence, unless indicated otherwise in a credit line to the material. If material is not included in the article's Creative Commons licence and your intended use is not permitted by statutory regulation or exceeds the permitted use, you will need to obtain permission directly from the copyright holder. To view a copy of this licence, visit http:// creativecommons.org/licenses/by/4.0/.

\section{References}

Actual, adj. and n. (2018) In: OED online. Oxford University Press. www.oed.com/view/Entry/1972. Accessed 18 Jan 2019

Alexius M (1960/1904) The theory of objects. In: RM Chisholm (eds) Realism and the background of phenomenology (I Levi, DB Terrell, RM Chisholm, Trans.). Free Press, Glencoe

Beall JC (2006) Towards non-being: the logic and metaphysics of intentionality. In: Notre dame philosophical reviews. <http://ndpr.nd.edu/reviewcfm?id=7503 > Accessed 26 Dec 2018

Beall JC (2013b) Modal Meinongianism and actuality. Humana Mente 25:155-176

Berto F (2013a) Existence as a real property. Springer, Dordrecht

Donnellan K (1966) Reference and definite descriptions. Philos Rev 75(3):281-304

Everett A (2013) The nonexistent. Oxford University Press, Oxford

Frederick K (2000) Negative existentials. In: Everett A, Hofweber T (eds) Empty names, fiction and the puzzles of non- existence. Center for the Study of Language and Information Publications, Stanford, CA, pp 95-116

\footnotetext{
${ }^{9}$ In this case, then, such a situation is best described by Anthony telling a story de re about an object $o$, be it existent or nonexistent, that he supposes to be an actual existent golden mountain. World $w *$ selected by the intentional operator "... believes that ...", with Anthony and the actual world as arguments is Anthony's suppositional world. At $w *, o$ is an actually existent golden mountain. For this reason, I-act needs to be blocked in the case of sentence 1 as well. In like fashion to the way I addressed sentence 13 and sentences 18-20 in $\S 3$, this use of "actual" is modally qualified by Anthony's suppositional state: if something is supposed to be actual, then it need not be actual. For that reason, sentence 1 on this interpretation does not have the damaging consequences that Everett thinks it has. Thanks to an anonymous reviewer for bringing this to my attention.
} 
Kaplan D (1989) Demonstratives. In: Almog J, Perry J, Wettstein H (eds) Themes from Kaplan. Oxford University Press, Oxford, pp 481-563

Kocurek AW (2016) The problem of cross-world predication. J Philos Logic 45:697-742

Kroon F (2003) Quantified negative existentials. Dialectica 57(2):149-164

Lewis DK (1970) Anselm and actuality. Nous 4(2):175-188

Lewis DK (1973) Counterfactuals. Blackwell, Oxford

Nolan D (1997) Impossible worlds: a modest approach. Notre Dame J Formal Logic 38:535-572

Parsons T (1980) Nonexistent objects. Yale University Press, New Haven

Predelli S (1998) Utterance, interpretation and the logic of indexicals. Mind Lang 13(3):400-414

Predelli S (2005) Contexts: meaning, truth, and the use of language. Oxford University Press, Oxford

Priest G (2011) Against against non-being. Rev Symb Logic 4:237-253

Priest G (2016) Towards non-being. Oxford University Press, Oxford

Recanati F (2010) Truth-conditional pragmatics. Oxford University Press, Oxford

Russell B (1905) Review of A. Meinong, Untersuchungen zur Gegenstandstheory und Psychologie. Mind 14:530-538

Salmon N (1987) Existence. Philos Perspect 1:49-108

Sauchelli A (2012) Fictional objects, non-existence, and the principle of characterization. Philos Stud 159:139-146

Wehmeier KF (2012) Subjunctivity and cross-world predication. Philos Stud 159:107-122

Yagisawa T (1988) Beyond possible worlds. Philos Stud 53:175-204

Zalta EN (1988) Intensional logic and the metaphysics of intentionality. MIT Press, Cambridge

Publisher's Note Springer Nature remains neutral with regard to jurisdictional claims in published maps and institutional affiliations. 